\title{
Pengaruh Manajemen Talenta terhadap Employee Engagement dan Work From Home sebagai Variabel Moderasi
}

\author{
Christian Daniel Mende ${ }^{1, *}$, Yustina Erti Pravitasmara Dewi ${ }^{2}$ \\ ${ }^{1,2}$ Fakultas Ekonomika dan Bisnis, Universitas Kristen Satya Wacana, Salatiga, Indonesia \\ "Email: mendechrisel@gmail.com
}

\begin{abstract}
The work from home phenomenon due to the pandemic triggers doubts on the governance of employee talent, including efforts to maintain its attachment or called employee engagement. Reduced direct interaction between employees or between leaders and employees leads to doubts on attachment to the organization, especially if it is associated with employees in Generation Y. Generation $Y$ is expected to show the same employee engagement between working in the office or when doing its work from home. This research aims to test the relationship of talent management to employee engagement generation $Y$ with work from home as a moderation variable. The sampling technique was accidental sampling of 201 Generation Y employees in Indonesia who practice work from home were involved as research samples. Data analysis techniques used analysis based on SEM (Structural Equation Model) with an evaluation of measurement and structural models for hypothesis testing. The results of this study indicate that talent management has a significant and positive effect on generation Y employee engagement and work from home has no significant and positive effect on the relationship between talent management and generation $Y$ employee engagement.
\end{abstract}

\begin{abstract}
Abstraksi: Fenomena work from home akibat pandemi mencetuskan keraguan pada tata kelola talenta karyawan, termasuk upaya mempertahankan keterikatannya atau disebut dengan employee engagement. Berkurangnya interaksi langsung antara karyawan atau antara pimpinan dan karyawan mengakibatkan keraguan pada keterikatan pada organisasi, terlebih jika dikaitkan dengan karyawan pada Generasi Y. Generasi Y diharapkan menunjukkan employee engagement yang sama antara bekerja di kantor atau ketika melakukan pekerjaannya dari rumah. Penelitian ini bertujuan untuk menguji pengaruh manajemen talenta terhadap employee engagement generasi Y dengan work from home sebagai variabel moderasi. Teknik pengambilan sampel yaitu accidental sampling kepada 201 karyawan Generasi Y di Indonesia yang mempraktikkan work from home terlibat sebagai sampel penelitian. Teknik analisis data menggunakan analisis berbasis SEM (Structural Equation Model) dengan evaluasi model pengukuran dan struktural untuk uji hipotesis. Hasil penelitian ini menunjukkan manajemen talenta berpengaruh signifikan dan secara positif terhadap employee engagement generasi Y dan work from home berpengaruh tidak signifikan dan secara positif terhadap hubungan antara manajemen talenta dan employee engagement generasi Y.
\end{abstract}

Keywords: employee engagement; manajemen talenta; work from home

\section{Pendahuluan}

Sumber daya manusia merupakan elemen kunci dari suatu perusahaan yang akan mendukung tata kelola organisasi yang efektif dan efisien (Armstrong \& Taylor, 2014). Berbagai cara dan strategi perlu dilakukan demi mengelolah dan mengembangkan sumber daya di perusahaan (Waspodo, Handayani, \& Paramita, 2013). Salah satu cara untuk pengelolaan SDM yaitu dengan implementasi manajemen talenta. Pidato visi Indonesia oleh Presiden Joko Widodo, menyebutkan manajemen talenta merupakan salah satu cara agar SDM Indonesia dapat bersaing di kancah global (Hutapea, 2019). Manajemen talenta menjadi tahap baru dalam menyelesaikan masalah (Isfahani \& Boustani, 2014) dan salah satu kunci kesuksesan perusahaan di era modern ini (Alsakarneh \&
Hong Chao, 2015). Melalui ANTARA News (2020) Deputi SDM dan Teknologi Informasi Kementerian BUMN Alex Denni menyatakan mengenai manajemen talenta yang menjadi salah satu elemen dalam mentransformasi BUMN dan Perusahaan.

Mempertahankan sumber daya yang mampu bersaing di kancah global ini membutuhkan dukungan dari karyawan yang loyal. Salah satu upaya mendapatkan karyawan loyal disarankan oleh Pandita \& Ray (2018) dengan menerapkan manajemen talenta sehingga tercipta karyawan yang terikat atau disebut sebagai employee engagement. Rasa keterlibatan atau komitmen terhadap pekerjaan mereka memastikan bahwa karyawan ini akan tetap bersama organisasi dalam jangka panjang. Pendapat ini mendukung hasil penelitian Rachman \& 
Dewanto (2016) yang menyebutkan bahwa untuk mencapai tujuan organisasi perlu adanya karyawan yang memberikan seluruh kemampuan terbaiknya dan sadar sepenuhnya akan tujuan dari perannya dalam organisasi, dan hal ini dapat ditemukan pada praktik employee engagement atau karyawan yang sudah terikat (engaged) (Rachman \& Dewanto, 2016).

Employee engagement bagi perusahaan menjadi tantangan karena angkatan kerja mengalami regenerasi, dengan hadirnya gelombang generasi baru dengan dinamika yang baru dalam persaingan yaitu generasi $\mathrm{Y}$ (Anggraini, Astuti, \& Prasetya, 2016). Generasi $\mathrm{Y}$ adalah generasi yang terlahir tahun 1980-2000 dan secara global mempunyai segmen tenaga kerja yang paling sedikit terlibat sehingga melibatkan Generasi $\mathrm{Y}$ dalam organisasi menjadi misi yang sangat penting (Naim \& Lenka, 2017). Karyawan generasi Y memiliki karakteristik yang berbeda dari generasi sebelumnya, sehingga pemahaman mengenai perbedaan mengelola Generasi Y akan mempermudah pemimpin menjalankan strategi pengelolaan bakat yang tepat dan menjadikan organisasinya kuat dengan karyawan yang terikat (engaged). Mengelola talenta pada karyawan Gen Y agar mencapai tingkatan employee engagement menjadi lebih menantang manakala pandemi Covid-19 juga terjadi di Indonesia. Pandemi tersebut memunculkan fenomena new normal yang ditunjukkan dengan bekerja dari rumah atau work from home, yang menjadi tantangan baru dalam pengelolaan SDM.

Work from home (WFH) adalah konsep kerja dengan fleksibilitas jam kerja dan pekerjaan yang dilakukan dari rumah karyawan (Utami, 2020). Trend work from home menjadi suatu pilihan bekerja dan bagi beberapa perusahaan menjadi keputusan yang permanen (Laucerene, 2020). Perubahan cara karyawan melakukan pekerjaannya menjadi work from home, diasumsikan akan membawa perubahan pada manajemen talenta, terutama pada kelompok karyawan Gen Y.

Penelitian Pandita \& Ray (2018) menunjukkan bahwa alat yang paling sukses agar karyawan tetap terlibat atau engaged dan berkomitmen pada pekerjaan mereka adalah manajemen talenta. Sejalan dengan itu, penelitian Ratnawati \& Subudi (2018), Hariyanto \& Ferdian (2019) mengatakan bahwa manajemen talenta berpengaruh positif dan signifikan terhadap employee engagement. Namun demikian, ilmu pengetahuan yang dinamis juga mencatat kritik mengenai implementasi manajemen talenta. Penelitian dari Kartikasari (2018) mengatakan bahwa manajemen talenta tidak berpengaruh secara signifikan terhadap employee engagement. Oleh karena itu, dengan fenomena dan hasil penelitian terdahulu, perlu dilakukan penelitian yang menguji kembali tentang manajemen talenta terhadap employee engagement dengan memodifikasi kedua penelitian tersebut dengan tambahan variasi baru, yaitu diteliti pada generasi Y dan tambahan variabel work from home sebagai moderator. Meninjau juga penelitian mengenai employee engagement masih sedikit dibahas dalam manajemen sumber daya manusia di Indonesia (Rachman \& Dewanto, 2016).

Berdasarkan belum adanya kesepakatan ilmiah mengenai kaitan antar variabel dan kesenjangan pada publikasi mengenai manajemen talenta, employee engagement dan work from home, maka dirumuskan masalah penelitian yang mempertanyakan tentang: (1). Apakah manajemen talenta mempengaruhi employee engagement karyawan generasi Y?; (2). Apakah work from home memoderasi pengaruh manajemen talenta terhadap employee engagement?

\section{Kajian Teori}

\section{Employee Engagement}

Bedarkar \& Pandita (2014) mengatakan bahwa employee engagement adalah masalah kepedulian terhadap para dalam suatu organisasi, karena employee engagement merupakan elemen penting untuk menentukan tingkat efektivitas organisasi, inovasi dan daya saing. Employee engagement terjadi ketika seseorang terhubung dengan organisasi atau orang lain secara sadar waspada dan secara emosi, melakukan tujuan dari perannya untuk melayani dengan kemampuan terbaiknya (Rachman \& Dewanto, 2016). Employee engagement juga ditemukan pada gagasan yang bersifat multidimensi sebagai pembangun perusahaan, dan dimensi itu diukur secara fisik, kognitif dan emosional 
(Bhatt, Sharma, \& Associate, 2019). Menurut Saks (2019) employee engagement memiliki anteseden karakteristik pekerjaan, dukungan organisasi, dukungan pengawas, hadiah dan pengakuan, keadilan prosedural, keadilan distributif. Konsukuensi atau outputnya adalah kepuasan kerja, komitmen organisasi, niat untuk keluar, stres dan tekanan.

\section{Manajemen Talenta}

Manajemen talenta adalah serangkaian proses komprehensif dan terintegrasi untuk menciptakan suatu kumpulan bakat dalam organisasi, demi mencapai tujuan organisasi. Proses manajemen talenta termasuk mengidentifikasi, mengembangkan, merekrut, mempertahankan dan menggunakan orangorang berbakat di organisasi (Armstrong \& Taylor, 2014). Penelitian Pandita \& Ray (2018) menyimpulkan bahwa manajemen talenta terbagi menjadi 6 tahap, yaitu: Perencanaan bakat, Akuisisi bakat, Pengembangan bakat, Penempatan bakat, Retensi bakat, dan Evaluasi bakat.

Manajemen talenta dimulai dengan bisnis strategi dan menandakan adanya kebutuhan akan permintaan di masa depan untuk orang-orang berbakat. Pada akhirnya, tujuannya adalah mengembangkan dan memelihara orang-orang berbakat. Menurut Armstrong \& Taylor (2014) unsur-unsur atau elemen yang membentuk proses manajemen talenta adalah talent planning, resourcing, talent identification, talent relationship management, talent development, talent retention, career management, dan management succession planning.

\section{Work From Home}

Work from home atau telework adalah konsep mengenai cara kerja yang fleksibel yang memungkinkan pekerja mendapat akses bekerja dari lokasi yang berbeda selain kantor dengan menggunakan informasi dan teknologi komunikasi sehingga pekerjaan yang dilakukan terselesaikan dengan baik (Mbaskool, 2020; Pérez, Sánchez, \& De Luis Carnicer, 2003; Savić, 2020). Savić (2020) berpendapat bahwa work from home atau telework setidaknya memiliki 4 karakteristik, yaitu: (1) Seseorang yang merupakan karyawan perusahaan atau organisasi; (2) Keterlibatan pekerjaan aktual dengan organisasi atau perusahaan pada tugas tertentu; (3) Pekerjaan dilakukan di luar tempat fisik perusahaan; dan (4) Ada telekomunikasi dengan pimpinan. Work from home ditelaah oleh Nakrošienè, Bučiūnienè, \& Goštautaite, (2019) dengan mempertimbangkan intensitas, timework dan tempat kerja karyawan yang sedang telework. Faktor-faktor dan hasil telework yaitu kepuasan keseluruhan dengan telework, keuntungan yang dirasakan dari telework, peluang karier subyektif, dan produktivitas.

\section{Generasi $Y$}

Generasi Y atau Gen Y adalah generasi yang terlahir tahun 1980-2000 (Naim \& Lenka, 2017). Stereotip kepada generasi Y (millennials) menyebutkan bahwa kelompok ini merupakan jenis karyawan multitasker, memberikan kontribusi tinggi pada organisasi secara signifikan tapi kurang dalam ketrampilan komunikasi (Hartman \& McCambridge, 2011). Menurut (Hornbostel, Kumar, \& Smith, 2011) dalam penelitiannya juga memberikan beberapa gambaran dari karakteristik dan sikap dari generasi Y. Disebutkan bahwa generasi Y memiliki nilainilai yang realisme, percaya diri yang tinggi, suka bersosialisasi dengan orang lain dan termasuk orang yang menyenangkan, cenderung dari keluarga campuran, media komunikasi yang digunakan menggunakan handphone atau melalui internet, orang yang terstruktur, tangguh, serta berorientasi pada prestasi

Mempertahankan dan membuat karyawan generasi Y menjadi engaged adalah hal yang berbeda. Kurangnya rasa keterlibatan antara karyawan semua generasi merupakan masalah kritis. Karyawan generasi Y salah satunya paling rentan, dikarenakan lebih memfokuskan kepada kesuksesan yang cepat dan ambisius yang tinggi (Hartman \& McCambridge, 2011).

\section{Keterkaitan antara Variabel}

Penelitian Ratnawati \& Subudi (2018) mengatakan bahwa sebaiknya perusahaan mempraktikkan manajemen talenta dengan lebih memperhatikan orang-orang yang berbakat di perusahaan dan memberikan apresiasi sehingga menghasilkan karyawan yang engaged karena manajemen talenta 
berpengaruh secara positif dan signifikan terhadap employee engagement. Didukung hasil penelitian Hariyanto \& Ferdian (2019) bahwa manajemen talenta berpengaruh signifikan terhadap employee engagement. Kebutuhan praktik manajemen talenta pada generasi Y agar engaged atau terikat menjadi makin meningkat seiring dengan perubahan cara bekerja karyawan akibat pandemi global, yakni bekerja dari rumah.

Bekerja di rumah menjadi lebih penting daripada di kantor (Savić, 2020). Hasil positif seperti peningkatan produktivitas, loyalitas dan rasa kepemilikan organisasi, kepuasan kerja, retensi karyawan, dan daya tarik karyawan menjadi keunggulan dalam pekerjaan melalui work from home (Bailey \& Kurland, 2002). Menurut Sardershmukh, Sharma, \& Golden (2012) telework memiliki dampak positif yaitu menurunkan tekanan kerja dan konflik peran. Berbeda dengan penelitian dari Caillier (2011) yang dilakukan di U.S Federal Government Agency yang mengatakan bahwa teleworkers secara intens maupun jarang tidak secara konsisten memiliki tingkat motivasi kerja yang lebih tinggi dari orang yang bekerja di kantor. Penelitian De Vries, Tummers, \& Bekkers (2019) juga mengatakan bahwa work from home memiliki efek negatif kepada pegawai negeri yaitu komitmen organisasi berkurang dan tidak mempengaruhi keterlibatan kerja.

Berdasarkan konsep manajemen talenta dan employee engagement pada Gen Y di situasi work from home, maka peneliti merumuskan hipotesis sebagai berikut:

H1: Terdapat pengaruh manajemen talenta terhadap employee engagement generasi $\mathrm{Y}$.

$\mathrm{H} 2$ : Work from home memoderasi pengaruh manajemen talenta terhadap employee engagement generasi Y.

\section{Metode}

Metode penelitian dilakukan secara kuantitatif dengan melakukan survei kepada Gen Y di beberapa daerah di Indonesia, salah satunya yaitu Provinsi Jawa dikarenakan memiliki populasi masyarakat terbanyak dan melakukan work from home. Populasi karyawan generasi $\mathrm{Y}$ yang work from home di Indonesia tidak terhitung (infinite population).
Teknik pengambilan sampel yaitu accidental sampling kepada 201 karyawan Generasi Y di Indonesia yang mempraktikkan work from home terlibat sebagai sampel penelitian. Peneliti menyimpulkan sampel penelitian yaitu 201 orang dengan landasan berpikir Hair minimal 100 sampel untuk survei bisnis (Haryono, 2017). Penyebaran kuesioner dilakukan secara acak dengan melibatkan sosial media dan asosiasi profesi serta komunitas praktisi human resources dan akuntansi di Indonesia yakni KPHRI, IAI, dan HIMPSI.

Pelaksanaan pengumpulan data penelitian dilakukan pada bulan OktoberDesember 2020. Employee engagement diukur dengan 15 item yang merupakan pengembangan dari Armstrong \& Taylor (2014) dan Saks (2019). Pengukuran manajemen talenta diukur dengan 16 item yang merupakan pengembangan dari Armstrong \& Taylor (2014) dan pengukuran work from home dengan 10 item pernyataan dari Nakrošienè et al. (2019).

Peneliti melakukan uji hipotesis asosiatif dengan menggunakan teknik Structural Equation modeling atau SEM untuk mengetahui pola antar variabel endogen dan eksogen dengan menggunakan program aplikasi SmartPLS. Pengujian melakukan SEM diuji model evaluasi pengukuran (inner model) untuk melihat validitas hingga reliabilitas dan evaluasi model struktural (outer model) guna menguji hipotesis.

\section{Hasil}

Profil responden terdiri dari perempuan sebanyak $60,20 \%$ sedangkan laki-laki berjumlah 80 dan presentase $39,80 \%$. Klasifikasi usia responden yaitu 20-24 tahun dengan presentase $25,37 \%$, usia 25-29 sebesar $6,97 \%$, usia 30-34 sebesar 56,72\%, dan 35-40 sebesar $10,95 \%$. Gambaran umum lainnya terhadap responden disajikan pada Tabel 1.

Berdasarkan tabel karakteristik dari 201 responden asal provinsi maka DKI Jakarta memimpin dengan nilai paling tinggi yaitu 49,25\% yang mana merupakan episentrum karyawan bekerja secara Work From Home. 
Tabel 1. Karakteristik Responden

\begin{tabular}{|c|c|c|c|}
\hline Kategori & Sub kategori & Frekuensi & Persentase \\
\hline \multirow{13}{*}{ Asal Provinsi } & DKI Jakarta & 99 & $49,25 \%$ \\
\hline & Jawa Barat & 31 & $15,42 \%$ \\
\hline & Banten & 36 & $17,91 \%$ \\
\hline & Sulawesi Utara & 10 & $4,98 \%$ \\
\hline & Sumatera Utara & 2 & $1,00 \%$ \\
\hline & NTT & 1 & $0,50 \%$ \\
\hline & Kepulauan Riau & 1 & $0,50 \%$ \\
\hline & Jawa Tengah & 13 & $6,47 \%$ \\
\hline & Jawa Timur & 2 & $1,00 \%$ \\
\hline & Kalimantan Barat & 1 & $0,50 \%$ \\
\hline & DI Yogyakarta & 3 & $1,49 \%$ \\
\hline & Sulawesi Selatan & 1 & $0,50 \%$ \\
\hline & Sumatera Selatan & 1 & $0,50 \%$ \\
\hline \multirow{4}{*}{ Jabatan } & Staff & 123 & $61,19 \%$ \\
\hline & Senior Staff & 26 & $12,94 \%$ \\
\hline & Junior Manager & 26 & $12,94 \%$ \\
\hline & Manager & 26 & $12,94 \%$ \\
\hline \multirow{14}{*}{ Industri Pekerjaan } & Keuangan dan Asuransi & 25 & $12,44 \%$ \\
\hline & Perdagangan & 34 & $16,92 \%$ \\
\hline & Pendidikan & 12 & $5,97 \%$ \\
\hline & Manufaktur & 13 & $6,47 \%$ \\
\hline & Seni, Hiburan dan Rekreasi & 6 & $2,99 \%$ \\
\hline & Informasi dan Komunikasi & 56 & $27,86 \%$ \\
\hline & Jasa Profesional & 16 & $7,96 \%$ \\
\hline & Pembangunan dan Properti & 2 & $1,00 \%$ \\
\hline & Administrasi Publik & 3 & $1,49 \%$ \\
\hline & Minyak dan Gas & 5 & $2,49 \%$ \\
\hline & Kesehatan dan Sosial & 9 & $4,48 \%$ \\
\hline & Akomodasi dan Makanan & 3 & $1,49 \%$ \\
\hline & Agrikultur & 2 & $1,00 \%$ \\
\hline & Lain-lain & 15 & $7,46 \%$ \\
\hline
\end{tabular}

Sumber: Data Primer, diolah (2021)

Berdasarkan tabel analisis deskriptif di atas dapat di ambil kesimpulan rata-rata penilaian dari keseluruhan pernyataan employee engagement, manajemen talenta dan work from home memiliki nilai yang dikategorikan baik.

Tabel 2. Analisis Deskriptif rata-rata variabel endogen dan eksogen

\begin{tabular}{clcc}
\hline No & \multicolumn{1}{c}{ Variabel } & Mean & Kategori \\
\hline 1. & Employee & 3.971 & Baik \\
& $\begin{array}{l}\text { Engagement } \\
\text { 2. }\end{array}$ & & \\
Manajemen Talenta & 3.915 & Baik \\
Work From Home & 3.668 & Baik \\
\hline
\end{tabular}

Evaluasi Outer Model (Model Pengukuran)

a. Uji Validitas Konstruk
Validitas indikator dilihat dari nilai Loading Factor (LF) berdasarkan instruksi. Sesuai aturan umum, nilai LF indikator $\geq 0,7$ dapat dikatakan valid. Namun, seiring perkembangannya ilmu penelitian nilai LF antara 0,5-0,6 masih dapat diterima (Haryono, 2017). Nilai loading factor tersebut dapat dilihat pada Gambar 1.

Gambar 1 tersebut merupakan hasil modifikasi model pengukuran dengan didrop indikator E11, EE2, EE12, EE15, MT5, MT4, WFH2 dan WFH4. Asumsi yang digunakan oleh peneliti adalah dengan batas bawah loading factor 0,5, maka dari itu seluruh nilai loading factor sudah memenuhi dan dilanjutkan pada tahap selanjutnya. 


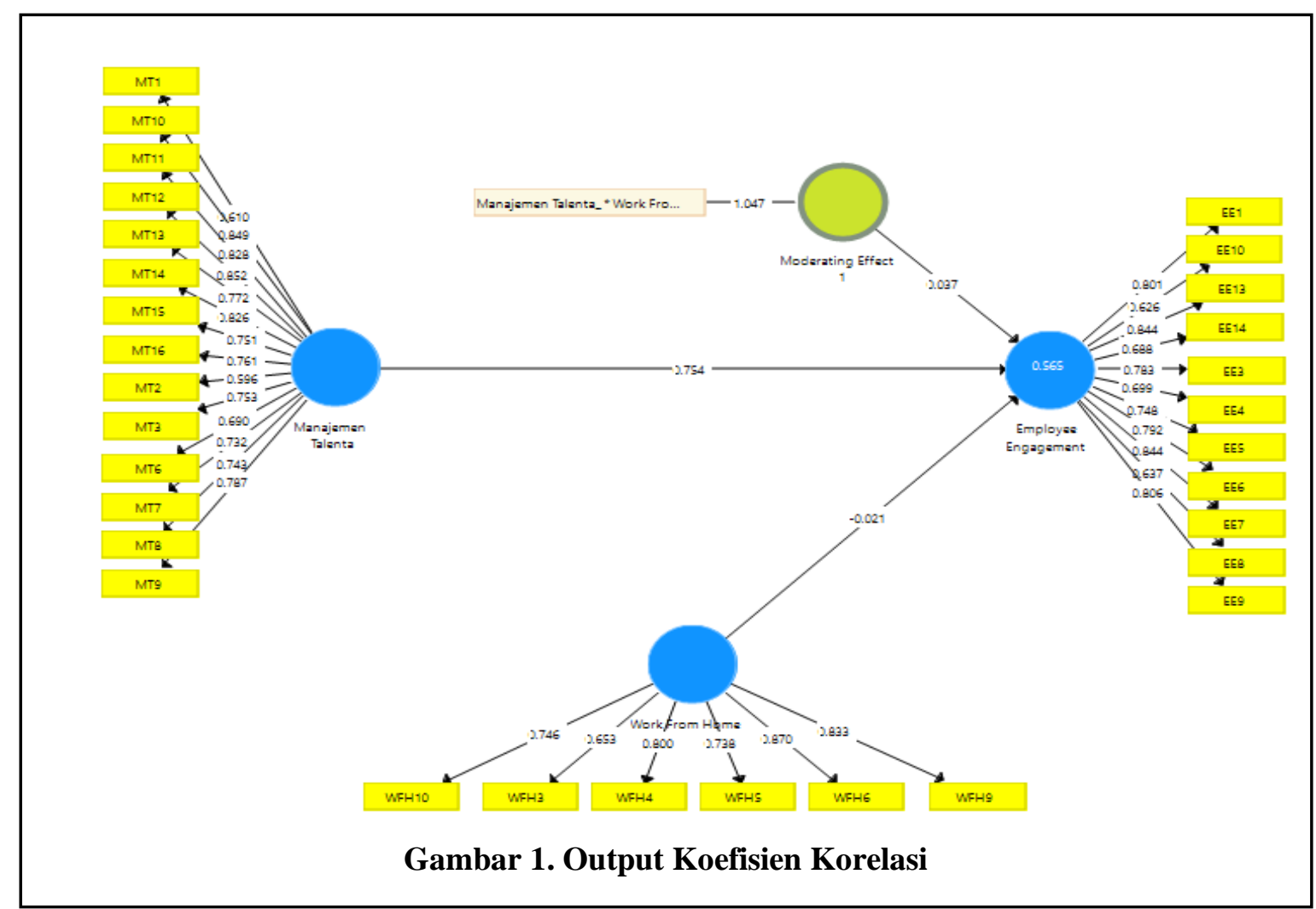

Ukuran lainnya untuk menilai convergent validity adalah nilai Average Variance Extracted (AVE). Nilai AVE juga dapat digunakan untuk menggambarkan besarnya varian atau keragaman yang dikandung dalam variabel latennya. Nilai kritis AVE $\geq 0,5$. Hasil nilai AVE untuk keseluruhan pada Tabel Hasil AVE di bawah sudah menunjukkan nilai yang melebihi batas. Dengan demikian, semakin besar varian indikator atau keragaman variabel manifest yang dapat dikandung oleh konstruk laten, maka semakin besar representasi variabel manifest terhadap konstruk latennya.

Tabel 3. Hasil AVE

\begin{tabular}{|c|c|}
\hline $\begin{array}{l}\text { Average } \\
\text { Variance } \\
\text { Extracted }\end{array}$ & (AVE) \\
\hline Employee Engagement_ & 0,571 \\
\hline Manajemen Talenta_ & 0,574 \\
\hline Moderating Effect 1 & 1,000 \\
\hline Work From Home_ & 0,603 \\
\hline $\begin{array}{l}\text { Pengujian berikutnya } \\
\text { mengevaluasi discriminant validity } \\
\text { cara melihat cross loading } \\
\text { membandingkan korelasi indikator } \\
\text { konstruknya dan konstruk blok } \\
\text { Kemudian membandingkan akar }\end{array}$ & $\begin{array}{r}\text { adalah } \\
\text { dengan } \\
\text { untuk } \\
r \text { dengan } \\
\text { lainnya. } \\
\text { kuadrat }\end{array}$ \\
\hline
\end{tabular}

AVE dengan korelasi antar konstruknya melalui Tabel 4.

Berdasarkan tabel Cross Loading di atas dapat disimpulkan bahwa masing-masing indikator dari tiap variabel laten mempunyai korelasi yang lebih besar dengan masingmasing konstruk pada bloknya dibandingkan dengan nilai koefisien korelasi indikator pada blok konstruk pada kolom lainnya. Hal ini menunjukkan bahwa konstruk tersebut memprediksi ukuran pada blok mereka dengan lebih baik dari blok lainnya.

Dari tabel di atas dapat disimpulkan bahwa konstruk memiliki nilai akar AVE lebih tinggi daripada korelasi antara konstruk dengan konstruk lainnya. Berdasarkan dua perhitungan tersebut melalui Cross Loading dan nilai akar AVE maka dapat dikatakan bahwa ukuran untuk discriminant validity sudah memadai.

b. Uji Reliabilitas Konstruk

Evaluasi terhadap nilai reliabilitas konstruk diukur dengan melihat nilai Cronbach's Alpha dan Composite Reliability. Nilai Cronbach's Alpha dan Composite Reliability semua konstruk harus $\geq 0.7$. 
Tabel 4. Cross Loading

\begin{tabular}{|c|c|c|c|c|}
\hline & $\begin{array}{l}\text { Employee } \\
\text { Engagement }\end{array}$ & $\begin{array}{l}\text { Manajemen } \\
\text { Talenta_ }\end{array}$ & $\begin{array}{l}\text { Moderating } \\
\text { Effect } 1\end{array}$ & $\begin{array}{l}\text { Work From } \\
\text { Home }\end{array}$ \\
\hline EE1 & 0,801 & 0,660 & 0,055 & 0,099 \\
\hline EE10 & 0,626 & 0,471 & 0,028 & 0,101 \\
\hline EE13 & 0,844 & 0,660 & 0,057 & 0,114 \\
\hline EE14 & 0,688 & 0,592 & 0,100 & $-0,004$ \\
\hline EE3 & 0,783 & 0,594 & 0,007 & 0,123 \\
\hline EE4 & 0,699 & 0,512 & 0,026 & 0,247 \\
\hline EE5 & 0,748 & 0,489 & 0,095 & 0,135 \\
\hline EE6 & 0,792 & 0,550 & $-0,002$ & 0,109 \\
\hline EE7 & 0,844 & 0,611 & 0,063 & 0,059 \\
\hline EE8 & 0,637 & 0,452 & $-0,020$ & 0,140 \\
\hline EE9 & 0,806 & 0,581 & 0,049 & $-0,034$ \\
\hline MT1 & 0,481 & 0,610 & $-0,010$ & 0,238 \\
\hline MT10 & 0,619 & 0,849 & 0,017 & 0,273 \\
\hline MT11 & 0,554 & 0,828 & $-0,037$ & 0,206 \\
\hline MT12 & 0,718 & 0,852 & 0,048 & 0,081 \\
\hline MT13 & 0,657 & 0,772 & 0,052 & 0,166 \\
\hline MT14 & 0,684 & 0,826 & $-0,002$ & 0,076 \\
\hline MT15 & 0,579 & 0,751 & 0,099 & 0,036 \\
\hline MT16 & 0,516 & 0,761 & $-0,008$ & 0,125 \\
\hline MT2 & 0,408 & 0,596 & 0,008 & 0,171 \\
\hline MT3 & 0,556 & 0,753 & $-0,013$ & 0,251 \\
\hline MT6 & 0,460 & 0,690 & $-0,011$ & $-0,028$ \\
\hline MT7 & 0,550 & 0,732 & 0,032 & 0,096 \\
\hline MT8 & 0,521 & 0,743 & 0,064 & 0,020 \\
\hline MT9 & 0,539 & 0,787 & 0,010 & 0,365 \\
\hline $\begin{array}{l}\text { Manajemen Talenta } \\
\text { * Work From Home }\end{array}$ & 0,057 & 0,025 & 1,000 & 0,032 \\
\hline WFH10 & 0,082 & 0,130 & $-0,010$ & 0,746 \\
\hline WFH3 & 0,084 & 0,244 & $-0,001$ & 0,653 \\
\hline WFH4 & 0,005 & 0,047 & $-0,001$ & 0,800 \\
\hline WFH5 & $-0,017$ & $-0,008$ & 0,068 & 0,738 \\
\hline WFH6 & 0,115 & 0,118 & 0,072 & 0,870 \\
\hline WFH9 & 0,090 & 0,106 & 0,032 & 0,833 \\
\hline
\end{tabular}

Tabel 5. Former Larcker (Perbandingan akar kuadrat AVE)

\begin{tabular}{llllll}
\hline & $\begin{array}{l}\text { Employee } \\
\text { Engagement__ }\end{array}$ & $\begin{array}{l}\text { Manajemen } \\
\text { Talenta_ }\end{array}$ & $\begin{array}{l}\text { Moderating } \\
\text { Effect 1 }\end{array}$ & \multicolumn{1}{l}{$\begin{array}{l}\text { Work From } \\
\text { Home_ }\end{array}$} \\
\hline Employee Engagement_ & 0,755 & & & & \\
\hline Manajemen Talenta_ & 0,750 & 0,758 & & \\
\hline Moderating Effect 1 & 0,057 & 0,025 & 1,000 & \\
\hline Work From Home_ & 0,126 & 0,194 & 0,032 & 0,776 \\
\hline
\end{tabular}

Tabel 6 memperlihatkan nilai Cronbach's Alpha dari employee engagement (0.923), manajemen talenta (0.942), Work From Home (0.885) dan moderating effect Work From Home* manajemen talenta $(1,000)$ yang semuanya lebih besar dari 0,7 . Kemudian lewat nilai $C R$ semua konstruk memiliki nilai di atas persyaratan. Melalui kedua kriteria ini menunjukkan bahwa konstruk sudah reliabel dengan kategori sangat baik.
Tabel 6. Cronbach's Alpha dan Composite Reliability

\begin{tabular}{lrr}
\hline & Cronb. Alpha & Comp. Reliability \\
\hline EE $_{-}$ & 0,923 & 0,935 \\
MT $_{-}$ & 0,942 & 0,949 \\
ME & 1,000 & 1,000 \\
WFH_ & 0,885 & 0,900 \\
\hline
\end{tabular}

Evaluasi Inner Model (Model Struktural)

Pengujian dalam pengukuran struktural untuk memvalidasi model dengan menggunakan $\mathrm{Q}^{2}$ predictive relevance. Hasil 
$\mathrm{Q}^{2}$ dikatakan baik jika nilainya > 0 , yang berarti model memiliki predictive relevance.

Tabel 7. Hasil Relevansi Prediksi $\left(\mathrm{Q}^{2}\right)$

\begin{tabular}{lrrr}
\hline \multicolumn{1}{c}{ SSO } & \multicolumn{1}{c}{ SSE } & $\mathrm{Q}^{2}(=1-\mathrm{SSE} / \mathrm{SSO})$ \\
\hline EE & 2211,000 & 1518,525 & 0,313 \\
MT & 2814,000 & 2814,000 & \\
ME 1 & 201,000 & 201,000 & \\
WFH & 1206,000 & 1206,000 & \\
\hline
\end{tabular}

Berdasarkan tabel 7, nilai $\mathrm{Q}^{2}$ yaitu 0.313 yang artinya model penelitian memiliki predictive relevance yang baik. Variabel laten eksogen baik sebagai variabel penjelas yang mampu memprediksi variabel endogennya.

Hasil R-Square terdiri dari tiga klasifikasi yaitu: nilai $\mathrm{R}^{2}$ 0.67, 0.33, dan 0.19 berturut-turut sebagai baik, moderat dan lemah.

\section{Tabel 8. R-Squared Value}

\begin{tabular}{lc}
\hline & $\begin{array}{c}\text { Employee } \\
\text { Engagement }\end{array}$ \\
\hline Original Sample $(\mathrm{O})$ & 0,565 \\
\hline Sample Mean $(\mathrm{M})$ & 0,582 \\
\hline Standard & 0,055 \\
Deviation (STDEV) & \\
\hline T Statistics (|O/STDEV|) & 10,183 \\
\hline P Values & 0,0000 \\
\hline
\end{tabular}

Berdasarkan tabel 8 R-Squared Value di bawah, $R^{2}$ adalah 0,565 yang berarti moderat atau interpretasinya adalah sebanyak $56 \%$ variabel laten endogen employee engagement dipengaruhi oleh variabel eksogen manajemen talenta dan work from home, sedangkan sisanya $44 \%$ dipengaruhi oleh variabel laten lainnya di luar penelitian ini.

\section{Uji Hipotesis}

Pengujian hipotesis melalui metode SEM dilihat dalam evaluasi model struktural pada nilai path coefficient dan $t$-Statistic pada Tabel 9. Dari Tabel 9 dapat dijelaskan sebagai berikut:

a. Hipotesis pertama atau $\mathrm{H} 1$

Dari tabel 9 dapat diketahui nilai $t$-Statistic yaitu antara variabel manajemen talenta terhadap employee engagement adalah sebesar $17.578 \geq 1.96$ dan ilai $P$ Value yaitu, $0.000 \leq 0.05$. Untuk nilai original sample $(\mathrm{O})$ yaitu 0.754 yang mengindikasikan positif. Oleh karena itu dapat disimpulkan bahwa: H1: Manajemen talenta (X) berpengaruh secara positif dan signifikan terhadap employee engagement $(\mathrm{Y})$.

b. Hipotesis kedua atau $\mathrm{H} 2$

Dari tabel di atas dapat diketahui nilai $T$ Statistic yaitu antara moderating effect terhadap employee engagement adalah sebesar $0.678 \leq 1.96$ dan nilai $P$ Value yaitu, $0.498 \geq 0.05$. Untuk nilai original sample $(\mathrm{O})$ yaitu 0.037 yang mengindikasikan positif. Oleh karena itu dapat disimpulkan bahwa: $\mathrm{H} 2$ : Work From Home (Z) berpengaruh secara positif namun tidak signifikan sebagai moderator terhadap manajemen talenta dengan employee engagement.

\section{Pembahasan}

Hasil penelitian menunjukkan bahwa manajemen talenta berpengaruh secara positif dan signifikan kepada employee engagement Generasi Y sehingga hipotesis yang menyatakan bahwa manajemen talenta mempengaruhi terhadap employee engagement diterima. Semakin tinggi manajemen talenta di suatu perusahaan maka employee engagement juga akan meningkat. Hasil penelitian ini juga mendukung penelitian yang dilakukan oleh Hariyanto \& Ferdian (2019), Pandita \& Ray (2018), Ratnawati \& Subudi (2018) bahwa manajemen talenta memiliki andil yang signifikan demi terciptanya tingkat employee engagement.

Penelitian ini juga menunjukkan bahwa karyawan yang berusia produktif atau generasi $\mathrm{Y}$ menyambut dengan baik jika manajemen perusahaan atau instansi lebih memperhatikan karier mereka, memberikan ruang promosi, memberikan programprogram mentoring atau coaching dan bentuk apresiasi-apresiasi lainnya untuk pengembangan bakat diri.

Tabel 9. Path Coeffients

\begin{tabular}{lcrrrrr}
\hline & $\begin{array}{l}\text { Original } \\
\text { Sample (O) }\end{array}$ & Mean (M) & $\begin{array}{l}\text { Standard Deviation } \\
\text { (STDEV) }\end{array}$ & \multicolumn{2}{l}{$\begin{array}{l}\text { T Statistics } \\
(\mid \mathbf{O} / \text { STDEV })\end{array}$} & P Values \\
\hline MT -> EE & 0,754 & 0,755 & 0,040 & 17,578 & 0,000 \\
\hline ME 1 -> EE & 0,037 & 0,021 & 0,057 & 0,678 & 0,498 \\
\hline WFH_-> EE & $-0,021$ & 0,001 & 0,063 & 0,314 & 0,758 \\
\hline
\end{tabular}


Hasil penelitian juga mendukung prinsip manajemen talenta yang dapat berperan secara maksimal dengan berpijak pada pandangan bahwa semua orang di perusahaan adalah orang yang berbakat dan layak diperjuangkan. Semakin terciptanya praktik talent planning, talent identification, talent relationship management, talent development dan career management maka akan semakin meningkat pula motivasi, komitmen dan rasa tanggung jawab karyawan terhadap perusahaan atau instansi. Hal ini mendukung penelitian Pandita \& Ray (2018) yang berkata bahwa manajemen talenta adalah alat yang paling sukses terhadap kontribusi meningkatkan keterlibatan karyawan yang dikonfirmasi juga oleh penelitian oleh Hariyanto \& Ferdian (2019).

Berdasarkan hasil penelitian ini, disarankan untuk manajemen setiap perusahaan atau instansi untuk tetap mempertahankan praktik-praktik yang baik mengenai manajemen talenta secara komprehensif, terencana dan tepat sasaran karena dengan demikian dapat meningkatkan keberlangsungan kesejahteraan karyawan, perusahaan dan tercapainya tujuan perusahaan. Langkah selanjutnya adalah terus meningkatkan pemahaman akan identifikasi talenta dengan mengimplementasikan program-program self development seperti mengikutkan dalam program sertifikasi pada lembaga profesi, training \& development dan bentuk-bentuk assessment lainnya yang dapat meningkatkan citra diri. Pada akhirnya hal ini akan membuat karyawan menyadari bakat atau potensi yang dimilikinya sehingga ia akan mengikatkan diri lebih lagi pada perusahaan.

Kedua, setiap manajemen perlu bersentuhan langsung dengan karyawan Generasi Y secara relevan dan adaptif. Membangun hubungan yang baik terus menerus dan mereduksi setiap kesenjangan antara pimpinan dan karyawan. Memberikan ruang sebesar-besarnya untuk komunikasi dengan meningkatkan talent relationship management. Oleh karena itu, manajemen perlu melakukan pendekatan-pendekatan interpersonal baik secara terencana maupun tidak terencana seperti pembinaan langsung atau mentoring yang relevan sesuai perkembangan jaman. Manajemen harus terbiasa dengan perubahan mengingat generasi $\mathrm{Y}$ adalah generasi yang cepat bosan. Ketiga, manajemen perlu meningkatkan ruang atau kesempatan bagi karyawan-karyawannya untuk bertumbuh. Dengan cara terus memberikan kesempatan dalam pengembangan karier, pemberian promosi dan bentuk apresiasi-apresiasi lainnya yang layak untuk diterima.

Hasil penelitian ini menunjukkan bahwa work from home berpengaruh tidak signifikan dan secara positif sebagai moderator terhadap hubungan antara manajemen talenta dan employee engagement. Penelitian ini juga mendapatkan hasil dari pengaruh langsung work from home terhadap employee engagement yaitu tidak signifikan dan secara negatif. Penelitian ini mendukung hasil penelitian De Vries et al. (2019) yang mengatakan bahwa work from home memiliki efek negatif yaitu komitmen organisasi berkurang dan tidak mempengaruhi keterlibatan kerja. Pernyataan ini juga didukung oleh Caiilier Gerard (2011) bahwa teleworkers tidak secara konsisten memiliki motivasi kerja lebih tinggi dari karyawan yang bekerja di kantor. Sejalan dengan itu, mendukung juga penelitian oleh Bellmann \& Hübler (2020) bahwa tidak ada efek yang jelas dari work from home terhadap kepuasan kerja, yang mana kepuasan kerja ini masih memiliki korelasi positif terhadap komitmen dan motivasi karyawan.

Berdasarkan hasil analisis deskriptif work from home rata-rata karyawan generasi $\mathrm{Y}$ di Indonesia merasakan intensitas dan keuntungan yang tinggi karena memiliki nilai yang baik, yaitu 3.9. Dengan demikian meskipun karyawan memiliki antusiasme yang tinggi terhadap work from home dan merasakan berbagai manfaatnya, namun hal tersebut tidak memiliki andil yang cukup terhadap peningkatan komitmen, motivasi dan rasa tanggung jawab lebih dari karyawan atau employee engagement. Pelaksanaan work from home akibat pandemi tidak mempengaruhi tingkat manajemen talenta terhadap employee engagement Generasi Y. Maka dari itu, praktik manajemen talenta pada karyawan Generasi Y di masa pandemi masih tetap relevan dan dibutuhkan untuk meningkatkan employee engagement. 


\section{Kesimpulan dan Saran}

Berdasarkan hasil penelitian dan pembahasan yang telah dijabarkan maka, dapat ditarik kesimpulan bahwa pertama terdapat pengaruh yang signifikan dan secara positif antara manajemen talenta dengan employee engagement karyawan generasi $\mathrm{Y}$ atau berusia produktif 20-40 tahun di Indonesia. Kedua, work from home tidak berhasil memoderasi hubungan antara manajemen talenta dengan employee engagement karena pengaruh yang dihasilkan adalah tidak signifikan dan secara positif. Mendukung hal tersebut ditemukan juga bahwa work from home berpengaruh tidak signifikan dan secara negatif terhadap employee engagement. Dengan demikian apabila karyawan Generasi Y bekerja dari rumah maka praktik manajemen talenta dan employee engagement dapat berjalan dengan baik. Temuan atas riset ini pada akhirnya mendukung praktik-praktik manajemen talenta seperti identifikasi bakat karyawan, talent relationship management, talent development dan career development sebagai variabel penting dalam mempertahankan employee engagement pada masa pandemi.

\section{Daftar Referensi}

Alsakarneh, A., \& Hong Chao, S. (2015). Talent Management in twenty-first century: theory and practically. International Journal of Applied Research.

Anggraini, L., Astuti, E., \& Prasetya, A. (2016). Faktor-Faktor Yang Mempengaruhi Employee Engagement Generasi Y (Studi Pada Karyawan PT Unilever Indonesia Tbk-Surabaya). Jurnal Administrasi Bisnis S1 Universitas Brawijaya, 37(2), 183-191.

ANTARA. (2020). Kementerian BUMN akan bangun tujuh elemen arsitektur SDM perusahaan. Retrieved July 21, 2020, from ANTARA NEWS website: https://www.antaranews.com/berita/158 5490/kementerian-bumn-akan-banguntujuh-elemen-arsitektur-sdm-perusahaan

Armstrong, M., \& Taylor, S. (2014). Armstrong's Handbook Of Human Resource Management Practice (13th ed.). Kogan Page.
Bailey, D. E., \& Kurland, N. B. (2002). A review of telework research: Findings, new directions, and lessons for the study of modern work. Journal of Organizational Behavior, 23(SPEC. ISS.), 383-400. https://doi.org/10.1002/job.144

Bedarkar, M., \& Pandita, D. (2014). A Study on the Drivers of Employee Engagement Impacting Employee Performance. Procedia-Social and Behavioral Sciences, 133, 106-115. https://doi.org/10.1016/j.sbspro.2014.04. 174

Bellmann, L., \& Hübler, O. (2020). Working from home, job satisfaction and worklife balance-robust or heterogeneous links? International Journal of Manpower. https://doi.org/10.1108/IJM10-2019-0458

Bhatt, R., Sharma, M., \& Associate, A. (2019). Employee Engagement: A Tool For Talent Management, Retention And Employee Satisfaction In The It/Ites Companies In India. International Journal of Research in Commerce \& Management, 10(8), 19-23.

Caillier, J. G. (2011). The Impact of Teleworking on Work Motivation in a U.S. Federal Government Agency. The American Review of Public Administration, 42(4), 461-480. https://doi.org/10.1177/0275074011409 394

De Vries, H., Tummers, L., \& Bekkers, V. (2019). The Benefits of Teleworking in the Public Sector: Reality or Rhetoric? Review of Public Personnel Administration, 39(4), p570-593. 24p. https://doi.org/10.1177/0734371X18760 124

Hariyanto, R. P. F., \& Ferdian, A. (2019). Pengaruh Talent Management Terhadap Employee Engagment. Jurnal Mitra Manajemen, 3(3), 273-285. Retrieved from http://ejurnalmitramanajemen.com/index.php/j $\mathrm{mm} /$ article/view/125/69

Hartman, J., \& McCambridge, J. (2011). Optimizing Millennials' Communication 
Styles. Bussiness and Professional Communication Quarterly, 74(1), 22-44. https://doi.org/https://doi.org/10.1177\% 2F1080569910395564

Haryono, S. (2017). Metode SEM Untuk Penelitian Manajemen dengan AMOS LISREL PLS (I; H. Mintardja, Ed.). Jakarta Timur: Luxima Metro Media.

Hornbostel, B., Kumar, P., \& Smith, R. (2011). My generation. 47.

Hutapea, E. (2019). Tingkatkan Kualitas Pendidikan, Jokowi Angkat 4 Isu Besar. Retrieved May 12, 2020, from Kompas website:

https://edukasi.kompas.com/read/2019/0 7/15/16080771/tingkatkan-kualitaspendidikan-jokowi-angkat-4-isu-besar

Isfahani, A. C.-, \& Boustani, H. (2014). Effects of Talent Management on Employees Retention: The Mediate Effect of Organizational Trust. International Journal of Academic Research in Economics and Management Sciences, 3(5), 114-128. https://doi.org/10.6007/ijarems/v3i5/1196

Kartikasari, M. P. N. (2018). Pengaruh Talent Management Dengan Perceived Organizational Support Sebagai Variabel Intervening Terhadap Employee Engagement Pada Pt Berlian Jasa Terminal Indonesia Surabaya. Jurnal Ilmu Manajemen (JIM), 6(4), 559-566.

Laucerene, S. (2020). Lengkap! Ini Panduan Menjalani New Normal Buat Karyawan. Retrieved from detikFinance website: https://finance.detik.com/beritaekonomi-bisnis/d-5027453/lengkap-inipanduan-menjalani-new-normal-buatkaryawan/1

Mbaskool. (2020). Work From Home. Retrieved June 17, 2020, from MBA SKOOL Team website: https://www.mbaskool.com/businessconcepts/human-resources-hrterms/16870-work-fromhome.html\#: :text=Definition\%3A Work From Home, or her job from home.\&text=Work from home is helpful,this option to their employees.
Naim, M. F., \& Lenka, U. (2017). The impact of social media and collaboration on Gen Y employees' engagement. International Journal of Development Issues, 16(3), 289-299. https://doi.org/10.1108/JJDI04-2017-0041

Nakrošienè, A., Bučiūnienė, I., \& Goštautaitė, B. (2019). Working from home: characteristics and outcomes of telework. International Journal of Manpower, 40(1), 87-101. https://doi.org/10.1108/IJM-07-20170172

Pandita, D., \& Ray, S. (2018). Talent management and employee engagementa meta-analysis of their impact on talent retention. Industrial and Commercial Training, 50(4), 185-199. https://doi.org/10.1108/ICT-09-20170073

Pérez, M. P., Sánchez, A. M., \& De Luis Carnicer, M. P. (2003). The organizational implications of human resources managers' perception of teleworking. Personnel Review, 32(6), 733-755+801. https://doi.org/10.1108/0048348031049 8693

Rachman, L., \& Dewanto, A. (2016). Pengaruh Employee Engagement terhadap Kepuasan Kerja dan Turnover Intention Perawat (Studi pada Rumah Sakit Wava Husada Kepanjen Malang). Jurnal Aplikasi Manajemen, 14(2). https://doi.org/10.18202/jam23026332.1 4.2.14

Ratnawati, D. P. D., \& Subudi, M. (2018). Pengaruh Talent Management Terhadap Employee Retention Dengan Employee Engagement Sebagai Variabel Mediasi Fakultas Ekonomi dan Bisnis Universitas Udayana, Bali , Indonesia Persaingan usaha pada era milenium saat ini ditandai dengan perubahan iklim bisni. E-Jurnal Manajemen Unud, 7(11), 6299-6325.

Saks, A. M. (2019). Antecedents and consequences of employee engagement revisited. Journal of Organizational Effectiveness, 6(1), 19-38. https://doi.org/10.1108/JOEPP-06-20180034 
Sardershmukh, S., Sharma, D., \& Golden, T. (2012). Impact of telework on exhaustion and job engagement: a job demands and job resources model. New Technology, Work and Employment, 27(3), 193-207. https://doi.org/https://dx.doi.org/10.1111 /j.1468-005X.2012.00284.x

Savić, D. (2020). COVID-19 and work from home: Digital transformation of the workforce. Grey Journal, 16(2), 101104.
Utami, F. (2020). Apa Itu Work From Home? Retrieved May 27, 2020, from Warta Ekonomi website: https://www.wartaekonomi.co.id/read27 6630/apa-itu-work-from-home/0

Waspodo, A. A., Handayani, N. C., \& Paramita, W. (2013). Pengaruh Kepuasan Kerja dan Stres Kerja Terhadap Turnover Intention pada Karyawan PT. Unitex di Bogor. Jurnal Riset Manajemen Sains Indonesia, 4(1), 97-115. 